\title{
The East Atlantic Oscillation: Mechanism and Impact on the European Climate in Winter
}

\author{
N.V. Mikhailova, A.V. Yurovsky \\ Marine Hydrophysical Institute, Russian Academy of Sciences, Sevastopol, \\ Russian Federation \\ e-mail: mikhailova_nv@mhi-ras.ru, a-yurovskiy@mhi-ras.ru
}

\begin{abstract}
The second leading mode of principal component analysis of the winter atmospheric pressure pattern in the North Atlantic-European region known as the East Atlantic Oscillation (EAO) is considered. The winter EAO pattern exhibits well-defined dipole at 500 -hPa geopotential height $\left(\mathrm{H}_{500}\right)$ with centers over the North Atlantic and the Central Europe. The EAO phase-to-phase shifts reflect the general atmospheric circulation changes and the zonal (meridional) circulation dominates in positive (negative) EAO phase. This induces storm tracks spatial shift, heat and moisture transport redistribution, which in turn results in anomalous winter air temperature and precipitation in the Europe. The surface air temperature and precipitation interannual variability explained by EAO index is $25-35 \%$ and $15-25 \%$, respectively. Positive EAO phase is associated with the higher winter air temperatures in Europe (mean anomalies are from +0.3 to $+3.5^{\circ} \mathrm{C}$ ), and negative EAO phase is associated with the lower winter air temperatures (mean anomalies are from -1.5 to $-0.5^{\circ} \mathrm{C}$ ).

Basin-wide changes in the intensity and location of the North Atlantic polar jet stream are observed between the EAO opposite phases. Anomalous cyclonic (anticyclonic) circulation over the North Atlantic and southward (northward) shift of the North Atlantic jet stream is shown to be inherent in positive (negative) EAO phase.
\end{abstract}

Keywords: East Atlantic Oscillation, surface air temperature, precipitation, midtropospheric jet, atmospheric circulation, storm tracks.

DOI: 10.22449/1573-160X-2016-4-25-33

(C) 2016, N.V. Mikhailova, A.V. Yurovsky

(C) 2016, Physical Oceanography

Introduction. Large-scale signals in the ocean-atmosphere system are an important object of research in climatology. Modern climate paradigm is based on idea of the existence of some stable states (modes) in the atmosphere, and the change of the climate conditions is considered as phase-to-phase transition. Largescale atmospheric signals, their spatial-temporal structure and variability are determined by multivariate statistical analysis. The first leading mode of climate variability in the Atlantic-European region defined by principal component analysis (PCA) of atmospheric pressure pattern is the North Atlantic Oscillation (NAO). The second leading mode is the East Atlantic teleconnection pattern or East Atlantic Oscillation (EAO).

Wallace and Gutzler [1] firstly described a set of Northern Hemisphere wintertime "teleconnection patterns" including the NAO and the East Atlantic. According to [1] the EAO centers of action are located to the south-west of the Canary Islands $\left(25^{\circ} \mathrm{N}, 25^{\circ} \mathrm{W}\right)$, between the Black and the Caspian Seas $\left(50{ }^{\circ} \mathrm{N}\right.$, $\left.40^{\circ} \mathrm{E}\right)$ and to the west of the UK $\left(55^{\circ} \mathrm{N}, 20^{\circ} \mathrm{W}\right)$. Later, having applied VARIMAX to 700 -hPa geopotential height pattern, Barnston and Livezey [2] determined the EAO principal center to be located to the west off the UK $\left(55^{\circ} \mathrm{N}, 20-35^{\circ} \mathrm{W}\right)$ and the center of opposite sign - close to the North Africa and the Mediterranean Sea $\left(25-35^{\circ} \mathrm{N}, 0-10^{\circ} \mathrm{W}\right)$. In recent papers [3-5] the EAO is defined as a pattern with a single center to the south of Iceland $\left(52.5^{\circ} \mathrm{N}, 22.5^{\circ} \mathrm{W}\right)$. 
According to different authors the second leading mode explains from $6 \%$ [2] to $23 \%$ [6] of the atmospheric pressure interannual variability in the AtlanticEuropean region. Thus, the scientists have demonstrated some contradictions related to the number of the EAO action centers, their geographic location and percentage of the explained variance.

The EAO as well as NAO has a significant impact on the atmospheric circulation and the European climate. Particularly, the EAO is shown to modulate precipitation to the south-west off the UK and across the Iberian Peninsula [7], and influence upon the principal storm-tracks and jet stream position over the North Atlantic $[6,8-11]$. In $[8,11]$ it was concluded that the NAO index to reflect the latitudinal changes of extratropical storm tracks and the EAO index - the changes in the integrated intensity and the number of cyclones. At the same time, on the basis of PCA of the 250-hPa zonal wind the authors of [12] determined the EAO to control the Atlantic jet stream expansion and narrowing but not its intensity. Thus, the relationship of the EAO, polar jet stream and cyclonic activity requires clarification. Moreover, in [11] only deep cyclones $(<1000 \mathrm{hPa})$ have been analyzed and the most active cyclogenesis areas in winter - the Mediterranean and the Black Sea - were outside the scope of the analysis, since central barometric pressure of the Mediterranean and the Black Sea cyclones was on average higher than $1000 \mathrm{hPa}$.

Changes of the hydrometeorological fields in relation to with any large-scale signal in the ocean-atmosphere system are well diagnosed and forecasted when the signal mechanism is known. Therefore, the aim of the present paper is to describe the EAO mechanism and its impact on the atmospheric circulation patterns, as well as on the surface air temperature and precipitation in the Atlantic-European region in winter season.

Data and methods. Air temperature and precipitation data (1950 - 2015) from E-OBS 11.0 gridded dataset [13], sea level pressure data Hadslp2 $(1870$ - 2015) from UK Met Office Hadley Centre [14], 500-hPa geopotential height $\left(H_{500}\right)$, 500-hPa zonal wind (1870 - 2015) from NCEP/NCAR 20CR reanalysis [15], monthly EAO and NAO indices (1950 - 2015) from NOAA Climate Prediction Centre (http://www.cdc.noaa.gov/ClimateIndices/) are used in the present paper. Storm tracks analysis is based on UK Met Office synoptic weather charts for 1998 - 2015 (http://www.wetterzentrale.de/topkarten/tkfaxbraar.htm) and Atlas of Extratropical Storm Tracks for 1961 - 1998 by NASA (USA) (http://data.giss.nasa.gov/stormtracks/).

In our study the standard PCA was applied to distinguish climate signals from sea level pressure and $\mathrm{H}_{500}$ data. Further research was performed using the composite method. The composites of the meteorological fields for positive and negative EAO phases were obtained by averaging the correspondent atmospheric characteristics for five years (1990, 1998, 2001, 2007 and 2014) with a positive winter EAO index and five years (1952, 1954, 1976, 1981 and 2012) with a negative one. These years were selected for the reasons that EAO index was the highest in absolute value, and NAO index was neutral (less than 1 in absolute value).

Results. The EAO pattern derived from PCA of the sea level pressure consists of one center located at $55^{\circ} \mathrm{N}, 20^{\circ} \mathrm{W}$ (Fig. 1, $a$ ). At $H_{500}$ two centers of different sign are identified: the first one - over the North Atlantic $\left(52^{\circ} \mathrm{N}, 30^{\circ} \mathrm{W}\right)$, the 
second, quite vast, but less intense - over Central Europe (Fig. 1, b). The second mode accounts for $20.1 \%$ of the sea level pressure total variance and $22.6 \%$ of $H_{500}$ total variance.


Fig. 1. The second leading mode spatial structure of the sea level pressure ( $a$ ) and $H_{500}(b)$ patterns in the Atlantic-European region in winter

Circulation indexes characterize temporal variability of the atmospheric modes. Analysis of the winter EAO index long-term variability derived for $H_{500}$ shows that until 1986 the negative phase of the signal dominated. Then positive and negative EAO phases with equal frequency were observed (Fig. 2). Thus since the beginning of 1950 the linear trend of the EAO index is fairly positive.

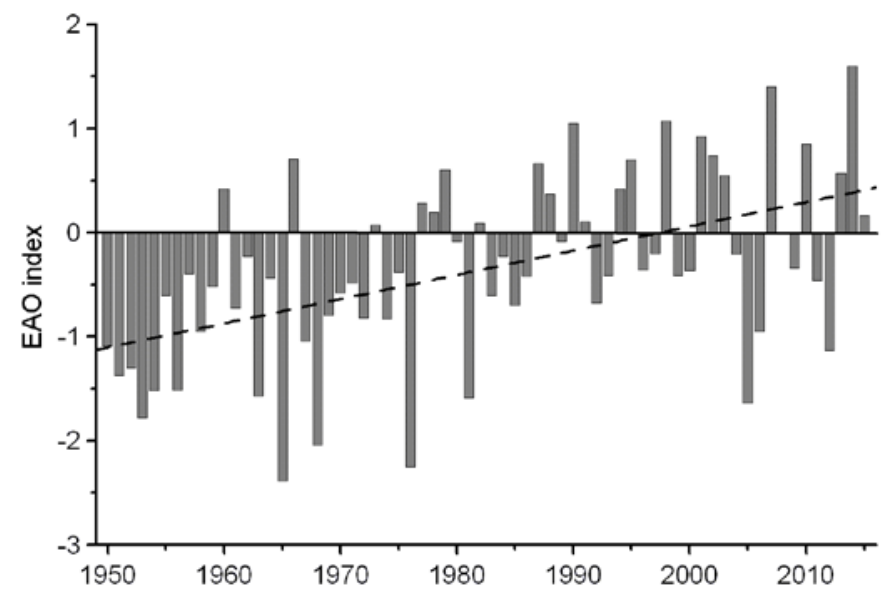

Fig. 2. Long-term variability of the winter EAO index and its linear trend 
In winter the sea level pressure anomalies have extreme values over the North Atlantic midlatitudes near the principal EAO center (Fig. 3). In the EAO positive (negative) phase the composite anomalies of sea level pressure measure up $+6 \mathrm{hPa}$ $(-4 \mathrm{hPa})$, respectively. A similar result was obtained in $[4,5]$.
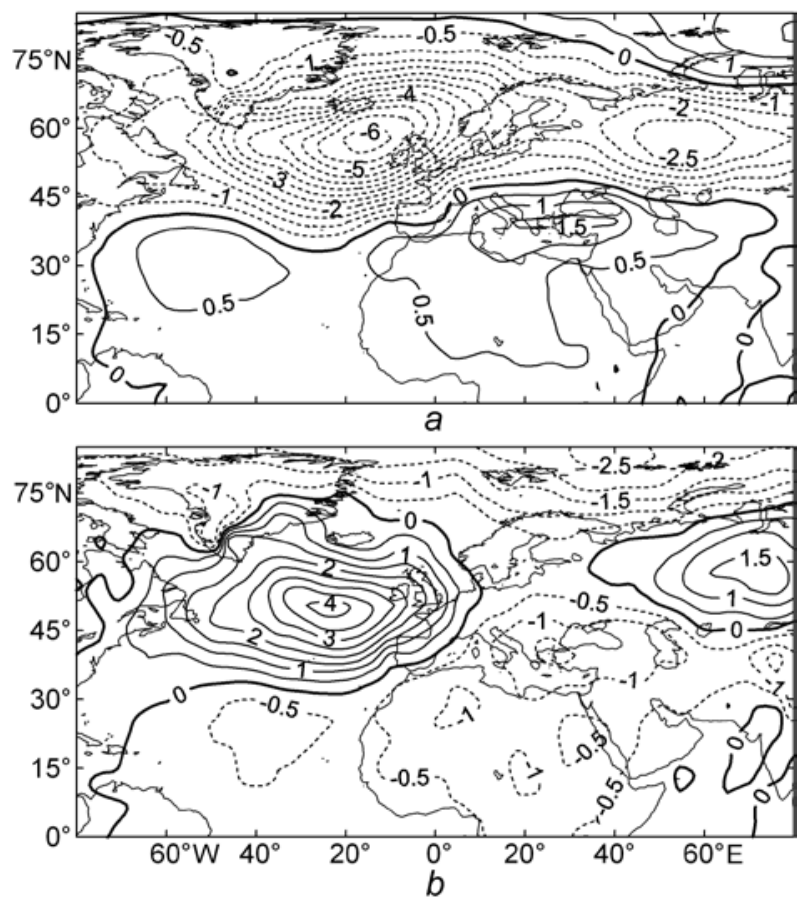

Fig. 3. Composite anomalies of the surface atmospheric pressure field (hPa) in the Atlantic-European region in the EAO positive $(a)$ and negative $(b)$ phases in winter relative to $1981-2010$

At $\mathrm{H}_{500}$ the EAO positive phase is characterized by strong westerlies over the Atlantic-European region (Fig. 4, a). The EAO negative phase is associated with the intense subtropical ridge located to the west off the European coast over the North Atlantic, and the trough stretching from the Barents to the Mediterranean seas (Fig. $4, b$ ). The cold trough over the Black and the Mediterranean seas in winter is a factor of the active cyclogenesis development over these areas. Consequently, during the EAO negative phase the cyclonic activity increase should be expected in the Black Sea and the Mediterranean region. Really, the results of [16] devoted to the classification of synoptic processes resulting in stormy situations over the Azov and the Black seas confirm this conclusion. The authors of [16] have demonstrated that under the zonal circulation type (the EAO positive phase) no storms occur, and under the $H_{500}$ field configuration shown in Fig. 4, $b$ (the EAO negative phase) $42 \%$ of all storms develop in the Azov-Black Sea region. Thus, in the Atlantic-European region in winter the EAO positive (negative) phase is characterized by the zonal (meridional) circulation type domination. 

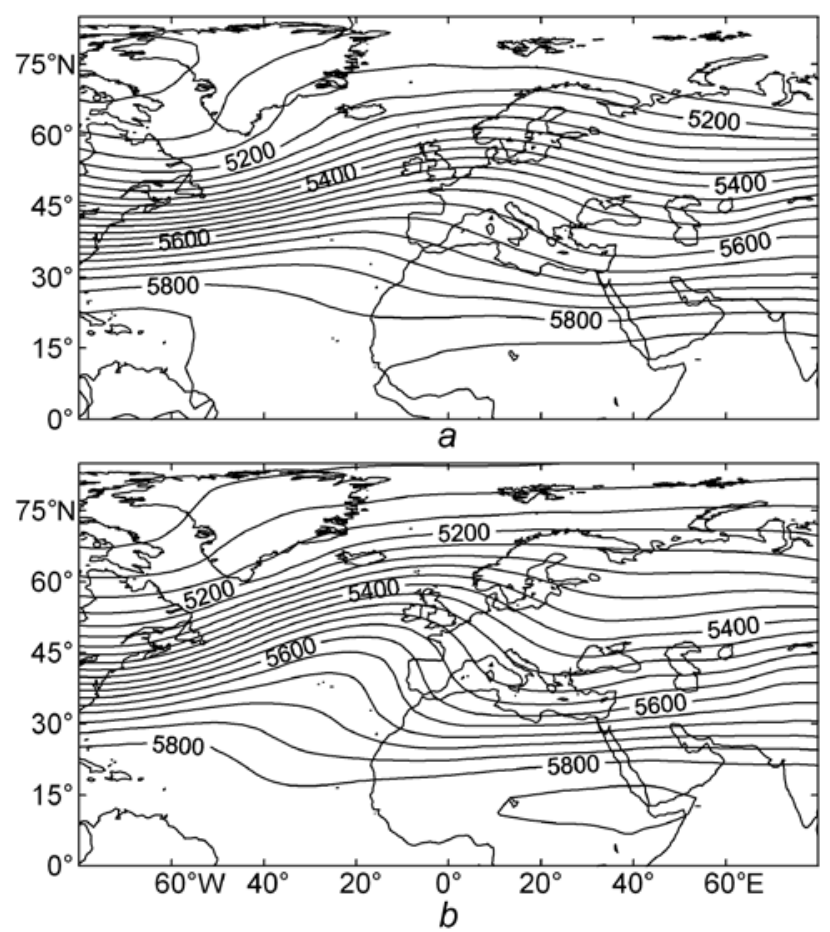

Fig. 4. Composite $H_{500}$ pattern in the EAO positive (a) and negative (б) phases in winter

The atmospheric pressure anomalies in different EAO phases are formed as a result of large-scale circulation changes in the Atlantic-European region. The analysis of synoptic charts showed that in the EAO positive phase the south-eastern part of the region was under the Siberian anticyclone influence and the northeastern one - under the Scandinavian or Arctic anticyclones impact. Besides, in the north of the Atlantic-European region the Greenland anticyclone goes strong. Along $50-60{ }^{\circ} \mathrm{N}$ a pathway for Atlantic cyclones appears (Fig. 5, a). These cyclones are very deep. The North Atlantic surface positive temperature anomalies favor their intensification. The cyclonic activity over the Mediterranean Sea has been suppressed that resulted in precipitation deficit in the southern Europe and in the Black Sea region. Winter in the most part of Europe during the EAO positive phase is mild. Air temperature anomalies range from +0.5 to $+3.5^{\circ} \mathrm{C}$.

The negative phase of the EAO is associated with the northeastward movement of the Azores anticyclone (Fig. 5, b). At the same time the north-eastern part of the Atlantic-European region is affected by the Siberian anticyclone ridges. Storm-tracks of the Atlantic cyclones go along the northern periphery of the Azores anticyclone or any large transient anticyclone formed over the North Atlantic. Then, through the Scandinavian Peninsula the cyclones penetrate to the north of Russia, bringing precipitation to this region. Some cyclones move along the ultrapolar paths supplying the Arctic regions with large amount of heat and moisture. Active process of the cyclogenesis is also observed over the eastern part of the Mediterranean Sea, Minor Asia and the Black Sea. Winter in the most part of Europe in the EAO negative phase is colder than usual. Air temperature anomalies range from -1.5 to $-0.5^{\circ} \mathrm{C}$. 

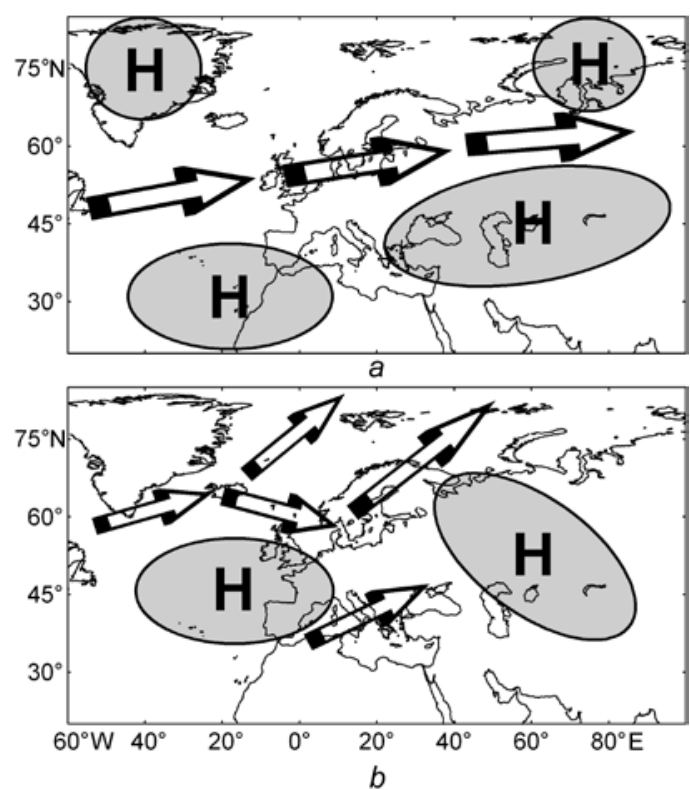

Fig. 5. Principal storm-tracks of the extratropical cyclones (indicated by arrows) and position of the main anticyclones in the positive $(a)$ and negative $(b)$ phases of the EAO in winter

The close positive relationship between the EAO index and surface air temperature in the European region is observed (Fig. 6, a). The correlation coefficients exceed 0.5 over the Central and 0.6 over Western Europe. Thus, 25 $35 \%$ of air temperature variability in the European region during the winter months is explained by the EAO.

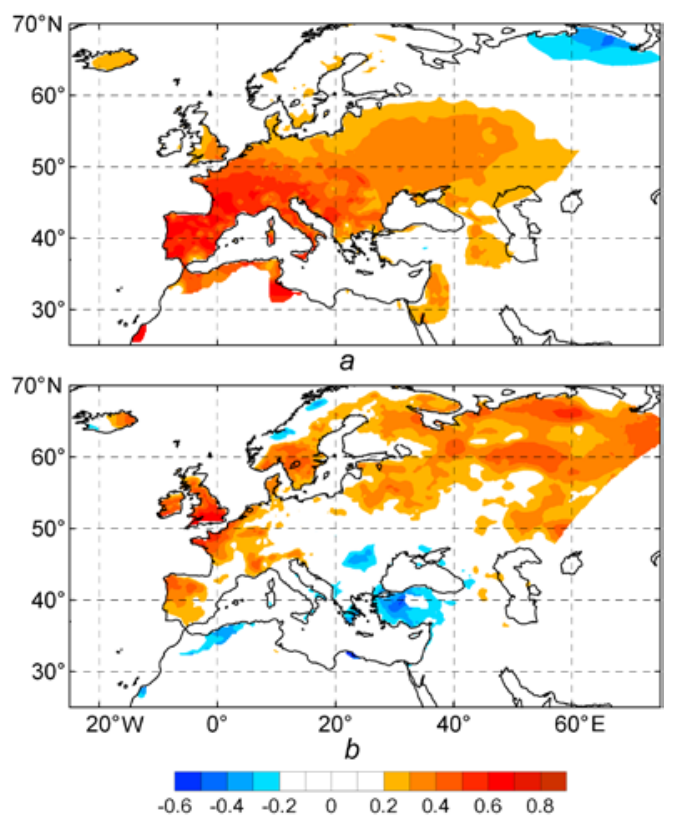

Fig. 6. Correlation between the EAO index and surface air temperature $(a)$ and precipitation $(b)$ in the European region in winter $(1950$ - 2015) 
Correlation field of the EAO index and precipitation exhibits zonal structure. The area of positive correlations is observed in the south of the Scandinavian Peninsula, the north of the European part of Russia and over the greater part of Western Europe. The negative correlations occupy the south of Central Europe and the north of the Scandinavian Peninsula (Fig. 6, b). The strongest positive relationship of the EAO index and precipitation $(R>0.6)$ is observed over the UK and the northern regions of France, while the area of negative correlation coefficients $(R<-0.6)$ is localized mainly to the south and west from the Black Sea - over Turkey and Romania. Consequently, on average 15 - 25 \% (and in some parts of the Europe up to $35 \%$ ) of the precipitation variability in the European region during the winter months is explained by the EAO. The correlation field agrees well with the described above features of the atmospheric circulation.

Since the storm-tracks are associated with the position of the jet stream in the middle troposphere, and the number of cyclones - with jet intensity [10, 17], it is obvious that the jet streams are the most important factor for climate formation. Let us consider the impact of two major climate signals (the NAO and EAO) on the jet stream parameters. According [17] in winter the jet stream over the North Atlantic is most often located in three latitudinal bands: $34-38^{\circ} \mathrm{N}, 42-46^{\circ} \mathrm{N}$ and $54-$ $58^{\circ} \mathrm{N}$ (Fig. 7, b). The extreme values of the correlation coefficients between the EAO index and the zonal wind at $500 \mathrm{hPa}$ fit these bands (Fig. 7, b). Thus, the EAO index values and a sign reflect changes in the mid-tropospheric jet position over the North Atlantic and its intensity. Note that jet intensification in the southern and central location occurs in the positive EAO phase, but in the negative EAO phase the jet is strengthened in the north of the region. Fig. 7 shows a similar correlation field of the NAO index. In contrast to the EAO, the NAO partially controls the jet stream velocity when the jet is in the northern and central positions.
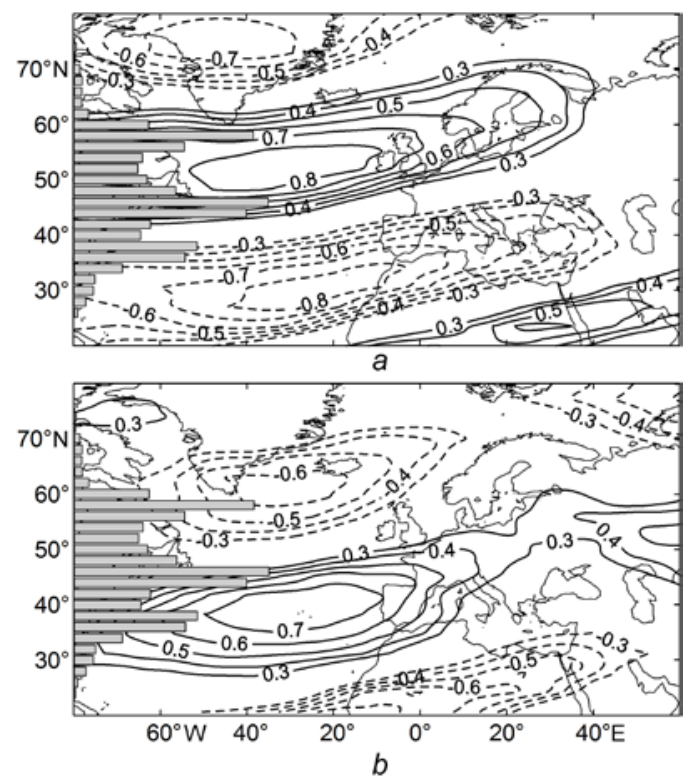

Fig. 7. The correlation between the NAO $(a)$ and EAO $(b)$ indices and the zonal wind at $500 \mathrm{hPa}$ (linear histogram shows distribution of the mid-tropospheric jet position in different latitudinal zones of the North Atlantic) [17]

PHYSICAL OCEANOGRAPHY NO. 4 (2016) 
Anomalies of the zonal wind at $500 \mathrm{hPa}$ indicate the EAO to serve a "switch" of the jet stream position over the Atlantics. In winter, in the positive EAO phase the anomalous cyclonic circulation appears over the North Atlantic (Fig. 8, a). At the same time westerlies increase in strength by $6-8 \mathrm{~m} / \mathrm{s}$ to the south of $45^{\circ} \mathrm{N}$ and decrease by $6-7 \mathrm{~m} / \mathrm{s}$ to the north of $57^{\circ} \mathrm{N}$. This means that jet stream is in the central or southern position, i. e. the cyclonic activity intensifies in the mid-latitudes and decreases in the polar regions.
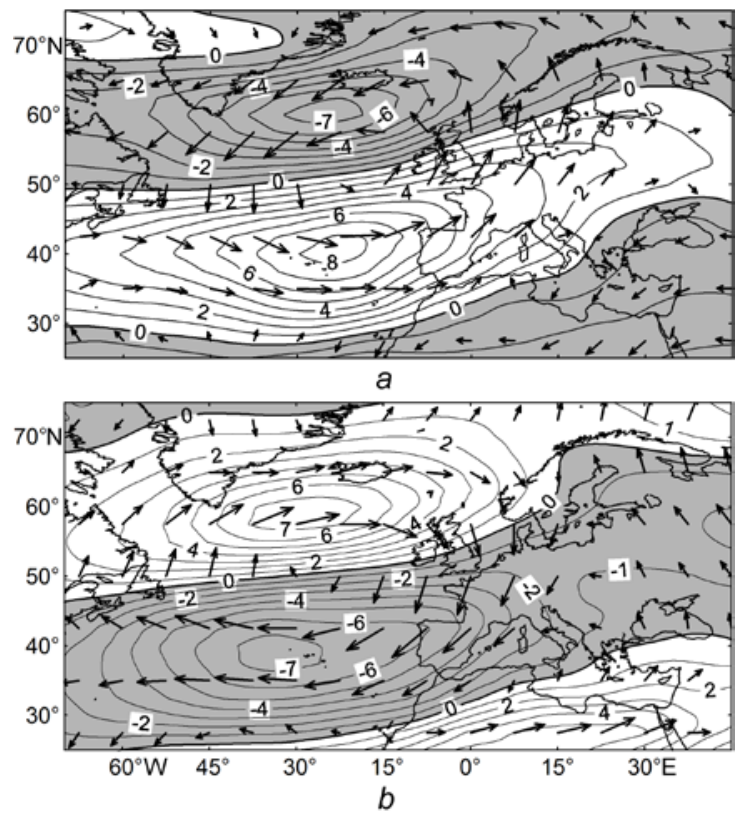

Fig. 8. Composite anomalies of the wind direction and zonal wind at $500 \mathrm{hPa}$ in winter relative to 1981 - 2010 in the EAO positive $(a)$ and negative $(b)$ phases (areas of the negative anomalies of the wind velocity are shadowed)

In the negative EAO phase the anomalous anticyclonic circulation is revealed over the Northern Atlantic (Fig. 8, b). The zonal wind is strengthened by $6-7 \mathrm{~m} / \mathrm{s}$ to the north of $57^{\circ} \mathrm{N}$ and is weakened by $6-7 \mathrm{~m} / \mathrm{s}$ to the south of $42{ }^{\circ} \mathrm{N}$. Consequently, the jet stream is located in the northern position, i.e. the cyclonic activity intensifies in the polar latitudes and decreases in the middle ones.

Conclusion. The joint analysis of the Eastern Atlantic Oscillation and atmospheric pressure field, geopotential height $H_{500}$, zonal wind at $H_{500}$, surface air temperature and precipitation in the Atlantic-European region in winter was carried out.

The atmposhere circulation type was found out to change in different EAO phases in the Atlantic-European region. In the positive (negative) EAO phase the zonal (meridional) circulation type prevails. This is reflected in the storm-tracks and has an impact on surface air temperature and precipitation in the region.

The surface air temperature and precipitation interannual variability explained by the EAO index is $25-35 \%$ and $15-25 \%$, respectively. The positive EAO phase is associated with the higher air temperature in the region in winter (mean 
winter air anomalies in Europe range from +0.5 to $+3.5^{\circ} \mathrm{C}$ ) and the negative EAO phase - with the lower ones (mean anomalies range from -1.5 to $-0.5^{\circ} \mathrm{C}$ ).

The East Atlantic Oscillation index is closely connected with the jet stream velocity in the middle troposphere over the Northern Atlantic. The EAO index sign is a perfect indicator of the jet latitudinal position.

\section{REFERENCES}

1. Wallace, J.M., Gutzler, D.S., 1981, "Teleconnections in the geopotential height field during the Northern Hemisphere winter”, Mon. Wea. Rev., no. 109, iss. 4, pp. 784-812.

2. Barnston, A.G., Livezey, R.E., 1987, "Classification, seasonality and persistence of lowfrequency atmospheric circulation patterns”, Mon. Wea. Rev., no. 115, iss. 6, pp. 1083-1126.

3. Nesterov, E.S., 2009, "O vostochnoatlanticheskom kolebanii tsirkulyatsii atmosfery [On the East Atlantic Oscillation of the atmosphere circulation]”, Meteorologiya i gidrologiya, no. 12, pp. 32-40 (in Russian).

4. Moore, G.W.K., Renfrew, I., 2012, "Cold European winters: Interplay between the NAO and the East Atlantic mode”, Atmos. Sci. Lett., no. 13, pp. 1-8.

5. Comas-Bru, L., McDermott, F., 2014, "Impacts of the EA and SCA patterns on the European twentieth century NAO - winter climate relationship”, Quart. J. Roy. Meteorol. Soc., no. 140, pp. 354-363, doi: 10.1002/qj.2158.

6. Woollings, T., Blackburn, M., 2012, "The North Atlantic jet stream under climate change, and its relation to the NAO and EA patterns”, J. Climate, no. 25, pp. 886-902.

7. Rodriguez-Puebla, C., Encinas, A.H. \& Nieto, S. [et al], 1998, "Spatial and temporal patterns of annual precipitation variability over the Iberian Peninsula”, Int. J. Clim., no. 18, pp. 299316.

8. Franzke, C., Feldstein, S.B., 2005, "The continuum and dynamics of Northern hemisphere teleconnection patterns”, J. Atmos. Sci., iss. 62, no. 9, pp. 3250-3267.

9. Seierstad, I.A., Stephenson, D.B. \& Kvamsto, N.G., 2007,”How useful are teleconnection patterns for explaining variability in extratropical storminess?", Tellus A, iss. 59, no. 2, doi: 10.1111/j.1600-0870.2007.00226.x.

10. Woollings, T., Hannachi, A., Hoskins, B., 2010, "Variability of the North Atlantic eddydriven jet stream”, Quart. J. Roy. Meteorol. Soc, no. 136, pp. 856-868.

11. Vyazilova, N.A., 2012, "Tsiklonicheskaya aktivnost' i kolebaniya tsirkulyatsii $v$ Severnoy Atlantike [Cyclonic activity and circulation oscillations in the Northern Atlantics]", Meteorologiya i gidrologiya, no. 7, pp. 5-14 (in Russian).

12. Athanasiadis, P.J., Wallace, J.M. \& Wettstein, J.J., 2010, "Patterns of wintertime jet stream variability and their relation to the storm tracks”, J. Atmos. Sci., no. 67, iss. 5, pp. 1361-1381.

13. Haylock, M.R., Hofstra, N. \& Klein Tank, A.M.G. [et al], 2008 "A European daily highresolution gridded dataset of surface temperature and precipitation”, J. Geophys. Res.: Atmospheres, no. 113, D20119, doi: 10.1029/2008JD1201.

14. Allan, R., Ansell, T., 2006, “A new globally complete monthly historical gridded mean sea level pressure dataset (HadSLP2): 1850 - 2004”, J. Clim., no. 19, pp. 5816-5842, doi: 10.1175/JCLI3937.1.

15. Compo, G.P., Whitaker, J.S. \& Sardeshmukh, P.D. [et al.], 2011, “The Twentieth Century Reanalysis Project”, Quart. J. Roy. Meteorol. Soc., no. 137, pp. 1-28.

16. Voskresenskaya, E.N., Naumova, V.A. \& Evstigneev, M.P. [et al.], 2009, “Klassifikatsiya sinopticheskikh protsessov shtormov $v$ Azovo-Chernomorskom basseyne [Classification of the synoptic processes of the storms in the Azov and Black Sea basin]", Naukovi pratsi Ukrains'kogo naukovo-doslidnogo gidrometeorologichnogo institutu, iss. 258, pp. 189-200 (in Russian).

17. Woollings, T., Czuchnicki, C. \& Franzke, C., 2014, “Twentieth century North Atlantic jet variability”, Quart. J. Roy. Meteorol. Soc., no. 140, pp. 783-791.

PHYSICAL OCEANOGRAPHY NO. 4 (2016) 